\title{
Dietary trans-10, cis-12-conjugated linoleic acid alters fatty acid metabolism and microbiota composition in mice
}

\author{
Tatiana M. Marques ${ }^{1,2}$, Rebecca Wall ${ }^{1,3}$, Orla O'Sullivan ${ }^{3}$, Gerald F. Fitzgerald ${ }^{1,2}$, Fergus Shanahan ${ }^{1}$, \\ Eamonn M. Quigley ${ }^{1}$, Paul D. Cotter ${ }^{1,3}$, John F. Cryan ${ }^{1,4}$, Timothy G. Dinan ${ }^{1,5}$, R. Paul Ross ${ }^{1,3}$ and \\ Catherine Stanton ${ }^{1,3 *}$ \\ ${ }^{1}$ Alimentary Pharmabiotic Centre, Biosciences Institute, University College Cork, Cork, Ireland \\ ${ }^{2}$ Department of Microbiology, University College Cork, Cork, Ireland \\ ${ }^{3}$ Teagasc Food Research Centre, Moorepark, Fermoy, Cork, Ireland \\ ${ }^{4}$ Department of Anatomy and Neuroscience, University College Cork, Cork, Ireland \\ ${ }^{5}$ Department of Psychiatry, University College Cork, Cork, Ireland
}

(Submitted 28 May 2014 - Final revision received 3 November 2014 - Accepted 10 November 2014 - First published online 20 February 2015)

\begin{abstract}
The main aim of the present study was to investigate the effects of dietary trans-10, cis-12-conjugated linoleic acid ( $t 10 c 12$-CLA) on intestinal microbiota composition and SCFA production. C57BL/6 mice ( $n 8$ per group) were fed a standard diet either supplemented with $t 10 c 12$-CLA $(0.5 \%, \mathrm{w} / \mathrm{w})$ (intervention) or with no supplementation (control), daily for 8 weeks. Metabolic markers (serum glucose, leptin, insulin and TAG, and liver TAG) were assessed by ELISA commercial kits, tissue long-chain fatty acids and caecal SCFA by GC, and microbial composition by $16 \mathrm{~S}$ rRNA pyrosequencing. Dietary $t 10 c 12$-CLA significantly decreased visceral fat mass $(P<0 \cdot 001)$, but did not affect body weight (intervention), when compared with no supplementation (control). Additionally, lipid mass and composition were affected by $t 10 c 12$-CLA intake. Caecal acetate, propionate and isobutyrate concentrations were higher $(P<0.05)$ in the $t 10 c 12$-CLAsupplemented group than in the control group. The analysis of the microbiota composition following 8 weeks of $t 10 c 12$-CLA supplementation revealed lower proportions of Firmicutes $(P=0.003)$ and higher proportions of Bacteroidetes $(P=0.027)$ compared with no supplementation. Furthermore, t10c12-CLA supplementation for 8 weeks significantly altered the gut microbiota composition, harbouring higher proportions of Bacteroidetes, including Porphyromonadaceae bacteria previously linked with negative effects on lipid metabolism and induction of hepatic steatosis. These results indicate that the mechanism of dietary $t 10 c 12$-CLA on lipid metabolism in mice may be, at least, partially mediated by alterations in gut microbiota composition and functionality.
\end{abstract}

Key words: trans-10, cis-12-Conjugated linoleic acid: Intestinal microbiota: Lipid metabolism

Conjugated linoleic acid (CLA) is a class of isomers of linoleic acid that occur naturally in dairy products and meat from ruminant animals due to bacterial biohydrogenation of ingested PUFA in the rumen ${ }^{(1)}$. CLA has been shown to be produced in vitro and in vivo by different species of bacteria ${ }^{(2-5)}$. Although cis-9, trans-11-CLA (rumenic acid) is the major natural form/isomer of CLA in foods, accounting for more than $90 \%$ of dietary CLA, mixtures containing equal amounts of cis-9, trans11-CLA and trans-10, cis-12-CLA ( $t 10 c 12-C L A)$ isomers are produced industrially and sold as supplements. Both the isomers exhibit significant biological activities, which may exert synergistic or antagonistic effects ${ }^{(1)}$. CLA has been shown to inhibit carcinogenesis $^{(6)}$, prevent atherosclerosis in different animal models $^{(7-9)}$, modulate the immune system ${ }^{(10,11)}$, and affect body composition, by reducing body fat and increasing lean body mass ${ }^{(12,13)}$. Also, $t 10 c 12$-CLA has been shown to be the isomer responsible for the anti-obesity effect attributed to CLA, and over the past years, its impact on body fat modulation has been largely studied in different animal models and in human subjects $^{(12-14)}$. There is evidence to suggest that fat mass reduction is the result of multiple interactions of $t 10 c 12-C L A$ with numerous metabolic signalling pathways, leading to decreased energy intake and increased energy expenditure, inhibition of adipogenesis and lipogenesis, modulation of adipokines and cytokines, and increased fatty acid (FA) $\beta$-oxidation in skeletal muscle ${ }^{(15)}$.

The response to CLA supplementation appears to be highly species-specific, with mice generally being more sensitive

Abbreviations: $t 10 c 12-C L A$, trans-10, cis-12-conjugated linoleic acid; FA, fatty acids; SREBP-1c, sterol regulatory element-binding protein 1c. 
than other animal models and human subjects. These differences are attributed to the dose levels used (human trials use lower doses), age (animal trials usually use young subjects), rate of body fat turnover (small animals have faster metabolism) and dietary regimens (ad libitum in animal models $v$. energy restriction in human trials ${ }^{(15,16)}$. In most studies using mice, body fat reduction induced by $t 10 c 12$-CLA supplementation is accompanied by adverse effects such as hepatic steatosis and hyperinsulinaemia ${ }^{(12,13)}$. These are features frequently associated with the metabolic syndrome, and commonly observed in obese and diabetic individuals ${ }^{(17,18)}$. Hepatic steatosis is characterised by an increase in liver mass with the accumulation of intracellular lipids, primarily in the form of TAG. Increased uptake of circulating FA, increased hepatic de novo lipogenesis, reduced rate of FA oxidation and reduced FA secretion are the multiple mechanisms leading to increased accumulation of lipids in the liver ${ }^{(19)}$

Moreover, recent studies have identified the gut microbiota as an environmental factor with an important role in host fat metabolism, and in the development of hepatic steatosis ${ }^{(17)}$. In a continuous bidirectional communication between the gut and the liver, hepatic products can directly influence the microbiota composition, whereas bacterial metabolites may have both direct and indirect effects on liver function and physiology ${ }^{(20,21)}$. Thus, in the present study, we investigated the impact of dietary t10c12-CLA supplementation on intestinal microbiota composition and SCFA production.

\section{Materials and methods}

\section{Animals and diets}

Experiments involving animals were carried out in accordance with the protocols approved by the Ethics Committee, University College Cork, under a license issued by the Department of Health and Children (Cruelty to Animal Act 1876, Directive for the Protection of Vertebrate Animals used for Experimental and other Scientific Purposes (89/609/ EEC)). Male C57BL/ 6 mice (7-8 weeks of age) were obtained from Charles River, and housed under barrier-maintained conditions within the Biological Services Unit, University College Cork. After 1 week of acclimatisation, the animals were divided into two groups ( $n 8$ per group). Both groups were fed ad libitum with a Teklad Global rodent standard diet (\#2018S; Harlan Laboratories) and allowed free access to water. The FA present in the diet included palmitic acid, stearic acid, oleic acid, linoleic acid and linolenic acid. The intervention group received the standard diet supplemented with $0.5 \%$ $(\mathrm{w} / \mathrm{w})$ t10c12-CLA (Matreya LLC; Table 1). Body weight was assessed weekly. After 8 weeks of dietary intervention, fasted animals were killed by decapitation, and blood samples were collected, allowed to clot for $2 \mathrm{~h}$ at $4^{\circ} \mathrm{C}$ and centrifuged at $2000 \mathrm{~g}$ for $20 \mathrm{~min}$. Liver, brain, fat pads (epididymal, perirenal and mesenteric), heart, kidneys and intestines were removed, blotted dry on a filter paper, weighed and flash-frozen in liquid $\mathrm{N}_{2}$. Caecal content was collected for the analysis of microbiota composition and SCFA concentrations. All samples were stored at $-80^{\circ} \mathrm{C}$ before analyses.
Table 1. Diet composition $(\mathrm{g} / 100 \mathrm{~g})$

\begin{tabular}{lcc}
\hline Ingredients & $\begin{array}{c}\text { t10c12-CLA- } \\
\text { supplemented }\end{array}$ & Unsupplemented \\
\hline Protein & $18 \cdot 6$ & $18 \cdot 6$ \\
Carbohydrate & $44 \cdot 2$ & $44 \cdot 2$ \\
Fat & $6 \cdot 7$ & $6 \cdot 2$ \\
Fatty acids & & \\
Palmitic & $0 \cdot 7$ & 0.7 \\
Stearic & $0 \cdot 2$ & $0 \cdot 2$ \\
Oleic & $1 \cdot 2$ & $1 \cdot 2$ \\
Linoleic & $3 \cdot 1$ & $3 \cdot 1$ \\
Linolenic & 0.3 & 0.3 \\
t10c12-CLA & 0.5 & - \\
Amino acids & $18 \cdot 4$ & 18.4 \\
Vitamins and minerals & $3 \cdot 7$ & 3.7 \\
\hline
\end{tabular}

t10c12-CLA, trans-10, cis-12-conjugated linoleic acid.

\section{Lipid extraction and fatty acid analysis}

FA profiles of the liver, brain, epididymal adipose tissue, heart and kidneys were analysed. Lipids were extracted with chloroform-methanol (Fisher Scientific), according to the method of Folch et al. ${ }^{(22)}$. After extraction, samples were methylated by using $0.5 \mathrm{M}-\mathrm{NaOH}$ (Sigma-Aldrich) in methanol for $10 \mathrm{~min}$ at $90^{\circ} \mathrm{C}$, followed by $10 \mathrm{~min}$ incubation at $90^{\circ} \mathrm{C}$ with $14 \%(\mathrm{w} / \mathrm{v})$ boron trifluoride in methanol (Sigma-Aldrich) ${ }^{(23)}$. FA methyl esters were recovered with hexane (Fisher Scientific). Before GLC analysis, samples were dried over anhydrous sodium sulphate (Sigma-Aldrich) for $1 \mathrm{~h}$, and stored at $-20^{\circ} \mathrm{C}$. FA methyl esters were separated using a Varian 3800 GC flame-ionisation system, fitted with a Chrompack CP Sil 88 column (Chrompack; $100 \mathrm{~m} \times 0.25 \mathrm{~mm}$ internal diameter, $0.20 \mu \mathrm{m}$ film thickness), and He gas as a carrier. The column oven was programmed initially at $80^{\circ} \mathrm{C}$ for $8 \mathrm{~min}$, and then increased by $8.5^{\circ} \mathrm{C} / \mathrm{min}$ to a final column temperature of $200^{\circ} \mathrm{C}$. The injection volume used was $0.6 \mu \mathrm{l}$, with automatic sample injection on an SPI 1093 splitless on-column temperature-programmable injector. Peaks were integrated using the Varian Star Chromatography Workstation version 6.0 software, and identified by comparison of retention times with pure FA methyl ester standards (Nu-Chek Prep, Inc.). The percentage of individual FA was calculated according to the peak areas, relative to the total area (total FA were set at 100\%). All FA results are expressed as $\mathrm{g} / 100 \mathrm{~g}$ FA methyl ester.

\section{SCFA concentration analysis}

Caecal content was vortex-mixed with Milli-Q water, incubated at room temperature for $10 \mathrm{~min}$, and centrifuged at $10000 \mathrm{~g}$ to pellet bacteria and other solids. The supernatant was filtered and transferred to a clear GC vial. 2-Ethylbutyric acid (Sigma) was used as the internal standard. The concentration of SCFA was analysed using a Varian 3500 GC flame-ionisation system, fitted with a Nukol-FFAP column $(30 \mathrm{~m} \times 0.32 \mathrm{~mm} \times 0.25 \mu \mathrm{m}$; Sigma). The initial oven temperature was set at $100^{\circ} \mathrm{C}$ for $0.5 \mathrm{~min}$, raised to $180^{\circ} \mathrm{C}$ at $8{ }^{\circ} \mathrm{C} / \mathrm{min}$ and held for $1 \mathrm{~min}$, then increased to $200^{\circ} \mathrm{C}$ at $20^{\circ} \mathrm{C} / \mathrm{min}$, and finally held at $200^{\circ} \mathrm{C}$ for $5 \mathrm{~min}$. The temperatures of the injector and the detector were set at 240 and $250^{\circ} \mathrm{C}$, respectively. 
He gas was used as a carrier at a flow rate of $1.3 \mathrm{ml} / \mathrm{min}$. A standard curve was built with different concentrations of a standard mix containing acetate, propionate, isobutyrate and $n$-butyrate (Sigma). Peaks were integrated by using the Varian Star Chromatography Workstation version 6.0 software. All SCFA data are expressed as $\mu \mathrm{mol} / \mathrm{g}$.

\section{Measurement of hepatic TAG concentrations}

Hepatic lipids were extracted according to the method of Folch et $a l^{(22)}$. After extraction, samples were dried under a stream of $\mathrm{N}_{2}$, and resuspended in a $5 \%(\mathrm{v} / \mathrm{v})$ solution of Triton X-100 in distilled water. TAG concentrations were measured using a commercial kit (EnzyChrom Triglyceride Assay; BioAssay Systems).

\section{Measurement of serum metabolic markers}

Commercial kits were used for the measurement of metabolic markers in serum. Glucose concentration was measured using the QuantiChrom Glucose Assay Kit (BioAssay Systems), TAG concentration using the EnzyChrom Triglyceride Assay Kit (BioAssay Systems), insulin concentration using the UltraSensitive Mouse ELISA Kit (Crystal Chem, Inc.), and leptin concentration using the Mouse Leptin ELISA Kit (Crystal Chem, Inc.).

\section{Amplicon sequencing of the gut microbiota}

For high-throughput amplicon sequencing, DNA was extracted from faecal samples using the QIAmp DNA Stool Mini Kit (Qiagen), according to the manufacturer's instructions, with the addition of a bead-beating step $(30 \mathrm{~s}, \times 3)$, and stored at $-20^{\circ} \mathrm{C}$. The microbiota composition of the samples was established by amplicon sequencing of the $16 S$ rRNA gene V4; universal $16 S$ rRNA primers estimated to bind to $94.6 \%$ of all $16 S$ genes (i.e. the forward primer (F1: 5'-AYTGGGYDTAAAGNG) and a combination of four reverse primers (R1: $5^{\prime}$-TACCRGGGTHTCTAAAGNG, R2: TACCAGAGTATCTAATTC, R3: 5'-CTACDSRGGTMTCTAATC and R4: 5'-TACNVGGGTATCTAATC); RDP'S Pyrosequencing Pipeline: http://pyro.cme.msu.edu/pyro/ help.jsp) were employed for PCR amplification. Molecular identifier tags were attached between the 454 adaptor sequence and the target-specific primer sequence, allowing for the identification of individual sequences from the pooled amplicons. The Ampure Purification System (Beckman Coulter) was used to clean the amplicons, before being sequenced on a 454 Genome Sequencer FLX platform (Roche Diagnostics Limited), in line with 454 protocols at the Teagasc high-throughput sequencing centre.

\section{Sequence analysis}

Raw sequences were quality-trimmed and filtered, using the QIIME Suite of programs ${ }^{(24)}$. The resulting trimmed FASTA sequences were assigned to taxa through BLAST analysis, against the SILVA database (version 106) for $16 S$ reads. BLAST outputs were parsed using MEGAN ${ }^{(25)}$ with a bit-score of 86; taxonomy was assigned to phylum, family and genus levels. Sequence reads were clustered, aligned and chimera-checked with Qiime, and phylogenetic analysis was implemented with FastTreeMP ${ }^{(26)}$. The relevant $\alpha$ - and $\beta$-diversities were calculated again using Qiime, and subsequently principal coordinate analysis was performed on distance matrices. Principal coordinate analysis plots were visualised with the KiNG viewer ${ }^{(27)}$.

\section{Statistical analysis}

To assess whether differences between treatment groups were significant, statistical analysis was performed by Student's $t$ test (Graph-Pad Software). Treatment effects with $P<0.05$ were considered significant. Kruskal-Wallis and Mann-Whitney tests, as implemented in the SPSS statistical software package, were used to find significant differences in microbial taxa and $\alpha$-diversity. Significance was considered as $P<0.05$. Data are presented as means with their standard errors.

\section{Results}

Effects of dietary trans-10, cis-12-conjugated linoleic acid on fat storage, liver weight, host metabolism and body weight

After 8 weeks of dietary supplementation with $t 10 c 12-C L A$, a 2-fold decrease in visceral body fat (sum of epididymal, mesenteric and perirenal fat pads; $P<0.001)$ and a significant increase in liver mass $(P<0 \cdot 01$; Table 2$)$ were found in the intervention group, compared with the unsupplemented control group. Body-weight gain and final body weight did not differ between the groups (Table 2). In addition, no difference in food intake was observed between the groups (Table 2). The greater liver weight observed in mice supplemented with $t 10 c 12-C L A$ was accompanied by a 7 -fold increase in hepatic TAG concentrations $(P<0 \cdot 001$; Table 2$)$.

Table 2. Effects of trans-10, cis-12-conjugated linoleic acid ( $t 10 c 12$ CLA) intake on body mass, liver mass and visceral fat mass, and on metabolic markers

(Mean values with their standard errors; $n$ 8)

\begin{tabular}{|c|c|c|c|c|}
\hline & \multicolumn{2}{|c|}{$t 10 c 12-C L A$} & \multicolumn{2}{|c|}{ Unsupplemented } \\
\hline & Mean & SE & Mean & SE \\
\hline Initial body weight (g) & $26 \cdot 7$ & 0.8 & $25 \cdot 4$ & 0.5 \\
\hline Final body weight $(\mathrm{g})$ & $31 \cdot 3$ & $1 \cdot 0$ & $30 \cdot 6$ & 0.9 \\
\hline Body-weight gain (\%) & $16 \cdot 0$ & $3 \cdot 0$ & $20 \cdot 5$ & $3 \cdot 1$ \\
\hline Food intake $(\mathrm{g})$ & 4.5 & 0.1 & $4 \cdot 3$ & 0.1 \\
\hline Absolute $t 10 c 12-C L A$ intake & 0.02 & 0.00 & - & - \\
\hline Liver weight $(\mathrm{g})$ & $2 \cdot 2^{\star \star}$ & 0.1 & 1.5 & $0 \cdot 1$ \\
\hline Visceral fat weight† (g) & $0 \cdot 6^{\star \star \star}$ & 0.06 & $1 \cdot 2$ & $0 \cdot 1$ \\
\hline Mesenteric fat weight (g) & $0.4^{\star}$ & 0.02 & 0.5 & 0.02 \\
\hline Perirenal fat weight $(\mathrm{g})$ & $0.03^{\star \star \star}$ & 0.00 & 0.16 & 0.02 \\
\hline Epididymal fat weight (g) & $0 \cdot 16^{\star \star *}$ & 0.03 & 0.55 & 0.06 \\
\hline Serum leptin $(\mathrm{ng} / \mathrm{ml})$ & $0 \cdot 7^{*}$ & 0.2 & $2 \cdot 4$ & 0.7 \\
\hline Serum glucose (mmol/l) & $11 \cdot 12^{\star \star}$ & 0.29 & $10 \cdot 18$ & 0.16 \\
\hline Serum insulin $(\mathrm{ng} / \mathrm{ml})$ & $4 \cdot 0^{\star}$ & 0.9 & $1 \cdot 7$ & 0.4 \\
\hline Serum TAG $(\mathrm{mmol} / \mathrm{l})$ & $0.32^{\star \star}$ & 0.05 & 0.69 & 0.09 \\
\hline Liver TAG $(\mathrm{mg} / \mathrm{g})$ & $20 \cdot 6^{\star * \star}$ & 2.9 & 2.9 & 0.2 \\
\hline
\end{tabular}

Mean value was significantly different from that of the unsupplemented control group: ${ }^{*} P<0.05,{ }^{* \star} P<0.01,{ }^{\star \star *} P<0.001$; Student's $t$ test.

† Visceral fat $=$ sum of epididymal, perirenal and mesenteric fat pads 
In contrast, serum TAG concentrations were lower in mice fed $t 10 c 12-C L A$, compared with the unsupplemented control mice $(P<0 \cdot 01)$. Also, $t 10 c 12$-CLA supplementation was associated with higher serum glucose $(P<0 \cdot 01)$ and serum insulin $(P<0.05)$ concentrations. Serum leptin concentration, which is proportional to the amount of fat in the body, was lower in the $t 10 c 12$-CLA-supplemented group than in the unsupplemented group $(P<0 \cdot 05$; Table 2$)$.

\section{Effects of dietary trans-10, cis-12-conjugated linoleic acid intake on host fatty acid composition}

FA profiles of the brain, epididymal adipose tissue, liver, heart and kidneys were analysed after 8 weeks of dietary $t 10 c 12$-CLA supplementation. The analysis revealed that $t 10 c 12$-CLA was incorporated into the epididymal adipose tissue, liver, heart and kidney tissues, but was not detected in the brain (Table 3 ). We did not detect $t 10 c 12$-CLA in any tissues of the unsupplemented control group. The FA composition of all tissues tested was significantly altered in the $t 10 c 12$-CLA-supplemented group compared with the unsupplemented control group, the greatest impact being observed on the brain, epididymal adipose tissue and liver (Table 3;

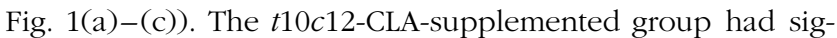
nificantly higher amounts of total SFA in the brain and epididymal adipose tissue than the unsupplemented control group $(P<0.001$; Fig. 1), including a 1.6-fold increase in myristic acid $(14: 0 ; P<0.05)$ and a $1 \cdot 2$-fold increase in palmitic acid (16:0; $P<0.001)$ in the brain, and a 2 -fold increase in myristic acid $(P<0.01)$ and palmitic acid $(P<0.001)$ in the epididymal adipose tissue (Table 3 ).

Moreover, the $t 10 c 12$-CLA-supplemented group had significantly lower amounts of myristic acid in the heart (57\%; $P<0.05)$ and lower amounts of stearic acid (18:0) in the epididymal adipose tissue $(17 \% ; P<0.05)$ and liver $(41 \%$; $P<0.001)$, whereas palmitic acid was higher in the liver $(13 \% ; P<0 \cdot 001)$. No differences were observed in the levels of SFA in the kidney of the $t 10 c 12$-CLA-supplemented group compared with the unsupplemented control group. Furthermore, $t 10 c 12-C L A$ supplementation was associated with reduced levels of MUFA in both epididymal adipose tissue and kidneys, while increased levels were found in the liver and brain (Table 3; Fig. 1). Higher amounts of palmitoleic acid (16:1-c9) were detected in the brain $(11 \% ; P<0.05)$ and lower amounts in the liver $(31 \% ; P<0.05)$, heart $(74 \%$; $P<0.05)$ and kidneys (56\%; $P<0.001)$ of the $t 10 c 12$-CLAsupplemented group. CLA supplementation also led to increased concentrations of oleic acid (18:1c9) in the liver $(50 \% ; P<0.001)$ and brain $(8 \% ; P<0.01)$, and decreased concentrations in the epididymal adipose tissue $(30 \% ; P<0 \cdot 01)$ and kidneys ( $19 \% ; P<0 \cdot 05) . n-3$ PUFA concentrations were also affected by $t 10 c 12$-CLA supplementation, with the brain of the intervention group having $24 \%$ less amounts of DHA (22: $6 n-3 ; P<0.001)$, and epididymal adipose tissue having $58 \%$ less amounts of linolenic acid (18:3n-3; $P<0 \cdot 001)$, $32 \%$ less amounts of docosapentaenoic acid (22:5n-3; $P<0.05)$ and $67 \%$ less amounts of DHA $(P<0.001)$ than those of the unsupplemented control group. The amount of
EPA (20: 5n-3) was 50\% lower $(P<0 \cdot 001)$, DHA 55\% lower $(P<0.001)$ and docosapentaenoic acid 33\% higher $(P<0.05)$ in the liver of the $t 10 c 12$-CLA-supplemented group compared with those of the unsupplemented control group. Moreover, the heart of the $t 10 c 12$-CLA-supplemented group had $57 \%$ less amounts of linolenic acid $(P<0.05)$ and $60 \%$ more amounts of docosapentaenoic acid $(P<0 \cdot 001)$, whereas the kidneys had $43 \%$ less amounts of linolenic acid $(P<0.01)$ and $45 \%$ more amounts of docosapentaenoic acid $(P<0.01)$ compared with the same tissues from the unsupplemented control group.

Furthermore, significant differences in $n-6$ PUFA composition were observed in the tissues of the intervention group. In the brain of these mice, arachidonic acid (20:4n-6) content was decreased by $21 \%(P<0 \cdot 001)$, while dihomo- $\gamma$-linolenic acid $(20: 3 n-6)$ content was increased by $67 \%(P<0 \cdot 001)$.

Linoleic acid (18:2n-6), dihomo- $\gamma$-linolenic acid and arachidonic acid concentrations in the epididymal adipose tissue of the intervention group were decreased by $32 \%$ $(P<0.001), 50 \%(P<0.001)$ and $29 \%(P<0.01)$, respectively. Significantly lower amounts of $\gamma$-linolenic acid (18: $3 n-6)$ (33\%; $P<0.001)$, dihomo- $\gamma$-linolenic acid $(22 \% ; P<0.001)$ and arachidonic acid ( $49 \% ; P<0.001)$ were also detected in the liver of these mice; less amounts of linoleic acid was detected in the heart $(14 \% ; P<0.05)$ and kidneys $(17 \%$; $P<0.05)$, whereas higher amounts of dihomo- $\gamma$-linolenic acid was detected in the kidneys $(50 \% ; P<0 \cdot 01)$. Furthermore, the relative proportion of SFA:MUFA, an important aspect of phospholipid composition and membrane fluidity, was altered in all tissues of these mice except the heart, and the ratio of $n$-6:n-3 PUFA was also changed, with higher $(P<0.05)$ proportions of $n-6$ PUFA in the brain, epididymal adipose tissue and liver (Table 3).

\section{Effects of trans-10, cis-12-conjugated linoleic acid intake on SCFA production}

Microbial fermentation in the caecum was enhanced by dietary supplementation with $t 10 c 12$-CLA. Acetate, propionate and isobutyrate levels were significantly higher $(P<0.05)$ in the $t 10 c 12$-CLA-supplemented group than in the unsupplemented control group, whereas no difference between the two groups was observed for $n$-butyrate. Moreover, total SCFA concentration (sum of acetate, propionate, isobutyrate and $n$-butyrate) was $34 \%$ higher in the caecal content of the t10c12-CLA-supplemented group than that of the unsupplemented control group ( $P<0 \cdot 05$; Fig. 2$)$.

\section{Effects of dietary trans-10, cis-12-conjugated linoleic acid intake on gut microbiota composition}

A total of 416309 V4 165 amplicon sequence reads were generated, corresponding to a mean of 23200 reads per mouse post-quality checking. All rarefaction curves were approaching parallel (data not shown), indicating sufficient depth of sequencing. Reads were clustered into operational taxonomical units of $97 \%$ identity, and diversity metrics estimated. Of the five $\alpha$-diversity metrics used (Shannon, 
Table 3. Effects of dietary trans-10, cis-12-conjugated linoleic acid (t10c12-CLA) intake on tissue fatty acid composition ( $\mathrm{g} / 100 \mathrm{~g}$ fatty acid methyl ester (FAME)) in mice (Mean values with their standard errors; $n$ 8)

\begin{tabular}{|c|c|c|c|c|c|c|c|c|c|c|c|c|c|c|c|c|c|c|c|c|}
\hline \multirow[b]{3}{*}{ FAME } & \multicolumn{4}{|c|}{ Brain } & \multicolumn{4}{|c|}{ Epididymal adipose tissue } & \multicolumn{4}{|c|}{ Liver } & \multicolumn{4}{|c|}{ Heart } & \multicolumn{4}{|c|}{ Kidney } \\
\hline & \multicolumn{2}{|c|}{$\begin{array}{l}t 10 c 12-C L A- \\
\text { supplemented }\end{array}$} & \multicolumn{2}{|c|}{$\begin{array}{l}\text { Unsupple- } \\
\text { mented }\end{array}$} & \multicolumn{2}{|c|}{$\begin{array}{l}\text { t10c12-CLA- } \\
\text { supplemented }\end{array}$} & \multicolumn{2}{|c|}{$\begin{array}{l}\text { Unsupple- } \\
\text { mented }\end{array}$} & \multicolumn{2}{|c|}{$\begin{array}{l}\text { t10c12-CLA- } \\
\text { supplemented }\end{array}$} & \multicolumn{2}{|c|}{$\begin{array}{l}\text { Unsupple- } \\
\text { mented }\end{array}$} & \multicolumn{2}{|c|}{$\begin{array}{l}\text { t10c12-CLA- } \\
\text { supplemented }\end{array}$} & \multicolumn{2}{|c|}{$\begin{array}{l}\text { Unsupple- } \\
\text { mented }\end{array}$} & \multicolumn{2}{|c|}{$\begin{array}{l}\text { t10c12-CLA- } \\
\text { supplemented }\end{array}$} & \multicolumn{2}{|c|}{$\begin{array}{l}\text { Unsupple- } \\
\text { mented }\end{array}$} \\
\hline & Mean & SE & Mean & $\mathrm{SE}$ & Mean & $\mathrm{SE}$ & Mean & $\mathrm{SE}$ & Mean & SE & Mean & SE & Mean & $\mathrm{SE}$ & Mean & $\mathrm{SE}$ & Mean & SE & Mean & $\mathrm{SE}$ \\
\hline \multicolumn{21}{|l|}{ SFA } \\
\hline $14: 0$ & $3 \cdot 1^{\star}$ & 0.4 & 1.9 & 0.1 & $2 \cdot 5^{\star \star}$ & 0.3 & $1 \cdot 1$ & 0.2 & 0.7 & $0 \cdot 0$ & 0.7 & 0.0 & $0.3^{*}$ & 0.0 & 0.7 & $0 \cdot 1$ & 0.8 & $0 \cdot 2$ & 0.7 & 0.1 \\
\hline $16: 0$ & $32 \cdot 9^{\star \star *}$ & $0 \cdot 6$ & $26 \cdot 7$ & 0.4 & $22 \cdot 9^{* * *}$ & 1.6 & $10 \cdot 7$ & 0.5 & $34 \cdot 2^{\star \star *}$ & 0.5 & $30 \cdot 4$ & 0.4 & 14.9 & 0.4 & $15 \cdot 7$ & 0.9 & $19 \cdot 9$ & 0.4 & $19 \cdot 0$ & 0.3 \\
\hline $18: 0$ & $11 \cdot 2$ & 0.1 & $11 \cdot 1$ & 0.2 & $1.9^{\star}$ & $0 \cdot 1$ & $2 \cdot 3$ & 0.0 & $5 \cdot 7^{\star \star \star}$ & 0.6 & $9 \cdot 6$ & 0.5 & $15 \cdot 0$ & 0.5 & $13 \cdot 4$ & $1 \cdot 1$ & $13 \cdot 7$ & 0.7 & $12 \cdot 7$ & 0.4 \\
\hline \multicolumn{21}{|l|}{ MUFA } \\
\hline $16: 1 c 9$ & $1 \cdot 0^{*}$ & 0.0 & 0.9 & 0.0 & $2 \cdot 9$ & 0.2 & $2 \cdot 8$ & $0 \cdot 1$ & $1 \cdot 8^{\star}$ & 0.2 & $2 \cdot 6$ & 0.2 & $0 \cdot 5^{\star}$ & $0 \cdot 1$ & 1.9 & 0.5 & $0.7^{\star \star \star}$ & $0 \cdot 1$ & 1.6 & $0 \cdot 1$ \\
\hline \multicolumn{21}{|l|}{$n-3$ PUFA } \\
\hline $18: 3 n-3$ & - & - & - & - & $1 \cdot 1^{\star \star \star}$ & 0.1 & $2 \cdot 6$ & 0.1 & 0.6 & 0.0 & 0.7 & 0.0 & $0.3^{*}$ & 0.0 & 0.7 & 0.1 & $0.4^{* \star}$ & 0.1 & 0.7 & 0.1 \\
\hline $20: 5 n-3$ & - & - & - & - & - & - & 0.1 & 0.0 & $0.1^{\star \star \star}$ & 0.0 & 0.2 & 0.0 & $0 \cdot 1$ & 0.0 & 0.1 & 0.0 & 0.2 & 0.0 & 0.2 & 0.0 \\
\hline $22: 5 n-3$ & 0.2 & 0.0 & 0.2 & 0.1 & $0.17^{\star}$ & 0.02 & 0.25 & 0.02 & $0.6^{*}$ & 0.1 & 0.4 & 0.0 & $2 \cdot 5^{\star \star \star}$ & 0.1 & 1.0 & $0 \cdot 1$ & $1 \cdot 1^{\star \star}$ & 0.1 & 0.6 & 0.1 \\
\hline \multirow{2}{*}{\multicolumn{21}{|c|}{$n-6$ PUFA }} \\
\hline & & & & & & & & & & & & & & & & & & & & \\
\hline $18: 2 n-6$ & 0.5 & 0.0 & 0.5 & 0.0 & $25 \cdot 1^{\star \star \star}$ & 1.6 & $36 \cdot 7$ & 0.7 & $17 \cdot 3$ & 0.9 & $19 \cdot 1$ & 0.3 & $19 \cdot 0$ * & 0.6 & $22 \cdot 0$ & 0.8 & $15 \cdot 6^{\star}$ & $1 \cdot 1$ & $18 \cdot 9$ & 0.7 \\
\hline $18: 3 n-6$ & 0.3 & 0.0 & - & - & $0 \cdot 1$ & 0.0 & 0.2 & 0.0 & $0.2^{\star \star \star}$ & 0.0 & 0.3 & 0.0 & - & - & - & - & - & - & - & - \\
\hline $20: 3 n-6$ & $0.5^{\star \star \star}$ & 0.0 & 0.3 & 0.0 & $0 \cdot 2^{\star \star *}$ & 0.0 & 0.4 & 0.0 & $0.7^{\star \star *}$ & 0.0 & 0.9 & 0.0 & $0.9^{\star \star}$ & $0 \cdot 1$ & 0.6 & 0.0 & 1.0 & $0 \cdot 1$ & 1.0 & 0.0 \\
\hline $20: 4 n-6$ & $4 \cdot 2^{\star \star \star}$ & 0.1 & 5.3 & 0.1 & $0.5^{\star \star}$ & 0.0 & 0.7 & 0.0 & $4 \cdot 0^{\star \star *}$ & 0.4 & $7 \cdot 8$ & 0.4 & $6 \cdot 3$ & 0.3 & $5 \cdot 2$ & 0.4 & 11.5 & 0.9 & $10 \cdot 4$ & 0.5 \\
\hline$t 10 c 12-C L A$ & - & - & - & - & $2 \cdot 2$ & 0.2 & - & - & 0.4 & 0.0 & - & - & 0.8 & $0 \cdot 1$ & - & - & 0.6 & $0 \cdot 1$ & - & - \\
\hline \multicolumn{21}{|l|}{ Ratios } \\
\hline MUFA:SFA & $0 \cdot 26^{*}$ & 0.0 & 0.28 & 0.0 & $1.00^{*}$ & 0.13 & 2.60 & $0 \cdot 10$ & $0.58^{*}$ & 0.05 & 0.33 & 0.02 & 0.33 & 0.03 & 0.50 & 0.08 & $0.34^{*}$ & 0.03 & 0.48 & 0.03 \\
\hline$n-6: n-3$ & $0.42^{*}$ & 0.0 & 0.34 & 0.0 & $17 \cdot 61^{*}$ & 0.72 & 10.86 & 0.35 & $6.86^{*}$ & 0.24 & 4.84 & 0.09 & 1.52 & 0.07 & 2.00 & 0.21 & $2 \cdot 43$ & 0.19 & 2.92 & 0.23 \\
\hline
\end{tabular}

Mean value was significantly different from that of the unsupplemented control group: ${ }^{\star} P<0.05,{ }^{\star \star} P<0.01,{ }^{* \star \star} P<0.001$; Student's $t$ test. 
Simpson, chao1, phylogenetic diversity and observed species), no significant differences were observed between the CLA-supplemented and unsupplemented control groups. The $\beta$-diversity value was calculated with both weighted and unweighted Unifrac distance matrices. The subsequent principal coordinate analysis revealed a distinct separation of the two groups for both measures (Fig. 3(a) and (b)).

The mouse gut microbiota was dominated by members of the Firmicutes and Bacteroidetes phyla. Microbial composition assignment revealed several significant differences between the CLA-supplemented and the unsupplemented control groups (Fig. 4 (a) and (b)). At the phylum level, $t 10 c 12-C L A$ supplementation significantly reduced the proportions of Firmicutes $(P=0.003)$ and increased the amounts of Bacteroidetes $(P=0.027)$, when compared with no supplementation. At the family level, the members of Desulfovibrionaceae $(P=0.027)$, Lachnospiraceae $(P=0.006)$, Family XIII Incertae Sedis $(P=0.016)$ and Peptococcaceae $(P=0.009)$ were all significantly decreased in the $t 10 c 12$-CLA-supplemented group, compared with the unsupplemented control group, while the members of Porphyromonadaceae $(P=0.002)$ were significantly increased in the $t 10 c 12$-CLA-supplemented group. At the genus level, the populations of Desulfovibrio $(P=0 \cdot 021)$, Lachnospiraceae Incertae Sedis $(P=0.006)$ and Ruminococcus Incertae Sedis $(P=0.027)$ were significantly decreased, and the populations of Odoribacter $(P=0.002)$ were significantly increased in the $t 10 c 12$-CLA-supplemented group when compared with the unsupplemented control group.

\section{Discussion}

The effects of dietary CLA supplementation on body fat have largely been studied in mice and, although the effects of $t 10 c 12$-CLA seem to be independent of genetic strain ${ }^{(28)}$, the C57BL/ 6 mouse has been shown to be very sensitive, and it constitutes a useful model for studying lipid metabolism
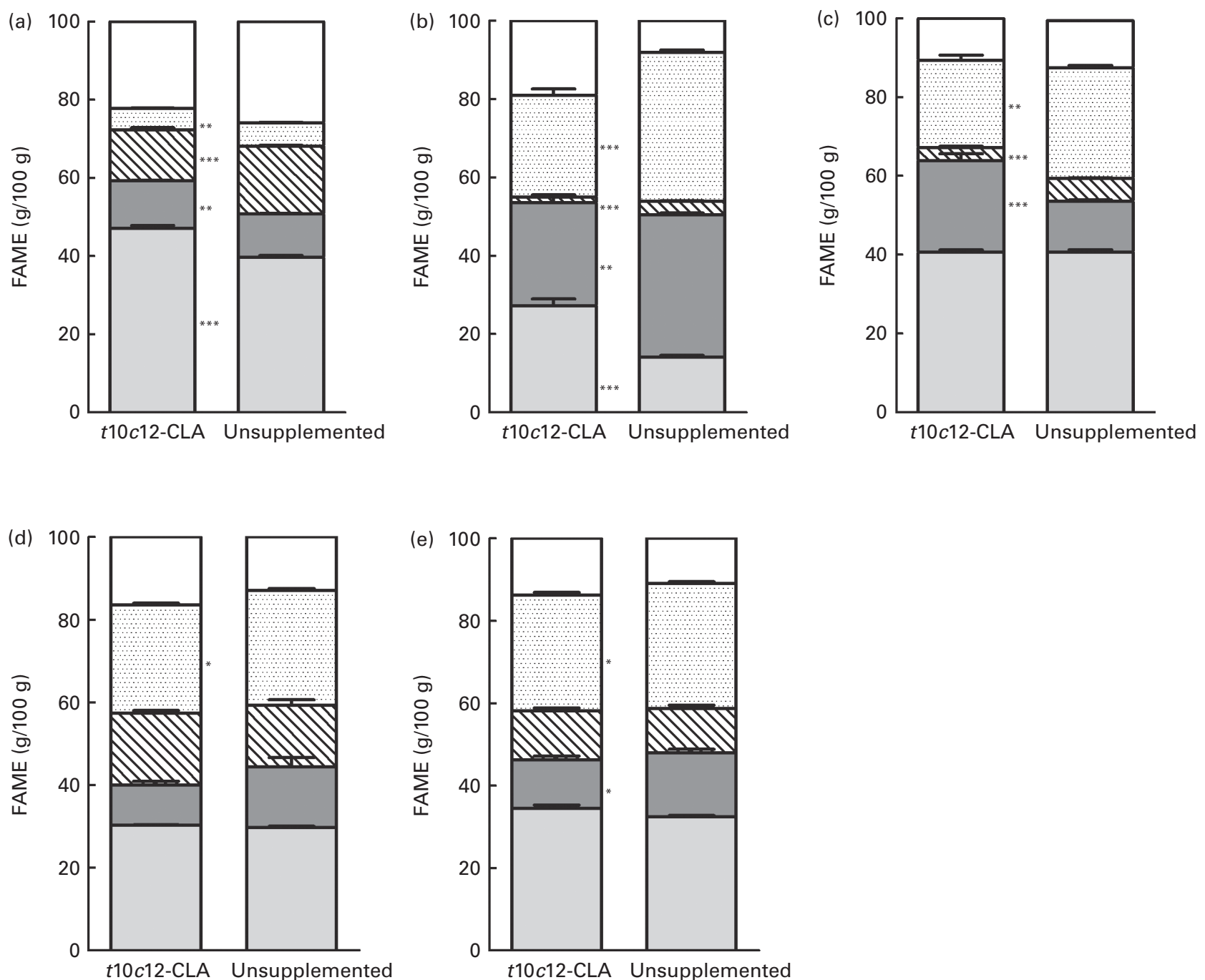

Fig. 1. Tissue fatty acid composition in mice fed a diet supplemented with trans-10, cis-12-conjugated linoleic acid (t10c12-CLA) or with no supplementation. The fatty acid composition was altered by $\$ 10 c 12$-CLA supplementation, with a greater impact on the (a) brain, (b) epididymal adipose tissue, (c) liver, (d) heart and (e) kidneys. Values are means, with their standard errors represented by vertical bars. Mean value was significantly different from that of the unsupplemented control group $\left({ }^{*} P<0.05,{ }^{\star *} P<0.01,{ }^{* * *} P<0.001\right.$; Student's $t$ test). FAME, fatty acid methyl esters. $\square$, SFA; $\square$, MUFA; $\mathbb{Q}$, PUFA $n-3 ;$;, PUFA $n-6 ; \square$, others. 


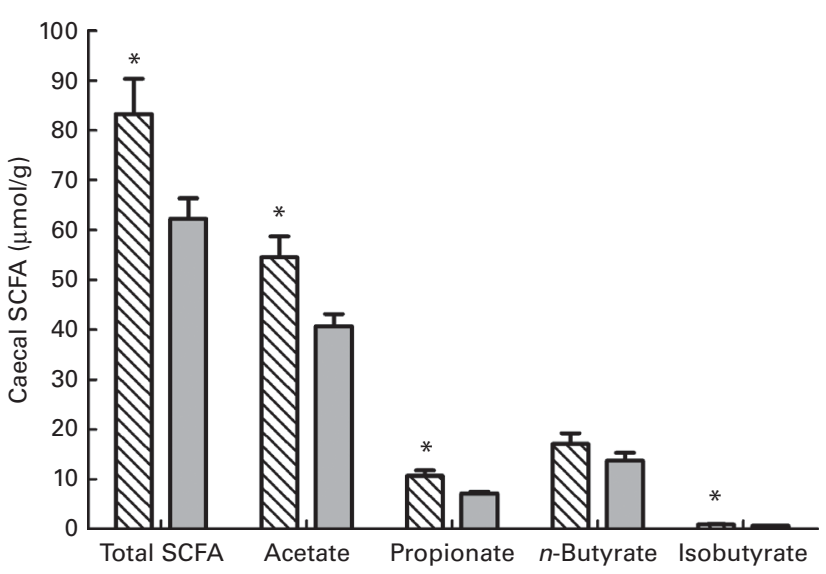

Fig. 2. Caecal SCFA concentrations in mice fed a diet supplemented with trans-10, cis-12-conjugated linoleic acid $(\mathbb{N})$ or with no supplementation ( $\square$, control group). Values are means $(n 8)$, with their standard errors represented by vertical bars. *Mean value was significantly different from that of the unsupplemented control group $(P<0.05$; Student's $t$ test).

dysfunction $^{(29)}$. Indeed, in the present study, C57BL/6 mice developed severe lipoatrophy with concomitant liver steatosis after 8 weeks of dietary supplementation with $0.5 \%(\mathrm{w} / \mathrm{w})$ $t 10 c 12$-CLA. Moreover, supplementation with $t 10 c 12$-CLA had a marked effect on the composition of the murine gut microbiota, when compared with no supplementation, despite no significant differences in diversity between groups (data not shown). Perturbations of the gut microbiota composition may play an important role in the development of diseases associated with altered metabolism such as obesity, diabetes and $\mathrm{CVD}^{(30)}$. For example, studies using germ-free animals have shown that the absence of the microbiota is accompanied by increased FA oxidation and decreased lipogenesis, making these animals resistant to diet-induced obesity, steatosis and insulin resistance ${ }^{(31,32)}$.

Furthermore, some evidence suggests that body-weight gain is associated with higher proportions of Firmicutes and lower proportions of Bacteroidetes in the gut microbiota ${ }^{(31,33,34)}$,

(a)

PC2 (15\%)

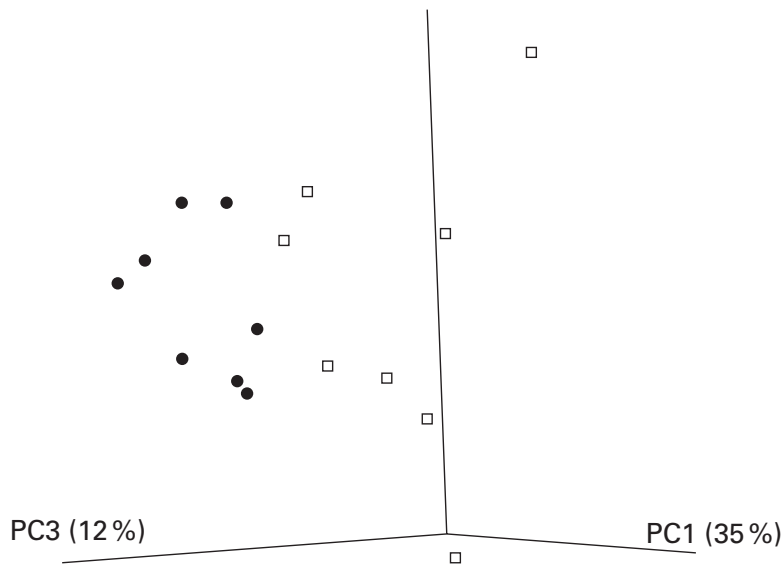

(b) while body-weight loss has been correlated with increased abundance of Bacteroidetes ${ }^{(35)}$. In the present study, we observed that decreased body fat in mice receiving $t 10 c 12$ CLA was associated with higher proportions of Bacteroidetes and lower abundance of Firmicutes. Interestingly, Larsen et $a l .{ }^{(36)}$ demonstrated the same compositional changes in the intestinal microbiota of human subjects with type 2 diabetes. Moreover, they showed that a higher Bacteroidetes: Firmicutes ratio correlates positively with higher blood glucose levels and lower body mass. As type 2 diabetes is usually associated with increased body weight, these findings led to the suggestion that overweight and diabetes are associated with different groups of the intestinal microbiota, and that levels of glucose tolerance should be considered when linking the microbiota with obesity and other metabolic diseases.

Membrez et al. ${ }^{(37)}$ further demonstrated that modulation of the gut microbiota with antibiotics influences whole-body glucose homeostasis, independent of body weight/body fat mass. In antibiotic-treated mice, reduced liver TAG levels correlated with improved insulin resistance, suggesting that the influence of the gut microbiota on glucose and liver metabolism may have similar mechanisms. The mechanism suggested for these changes was an increase in lipopolysaccharides, the main compound of the outer membrane of Gram-negative bacteria, such as bacteria from the Bacteroidetes phylum. Lipopolysaccharides have been shown to cause acute wholebody insulin resistance ${ }^{(38)}$, and are a potent stimulator of inflammation. Lipopolysaccharides activate Toll-like receptor 4 in the gut, leading to the expression of TNF- $\alpha^{(39)}$. Increased TNF- $\alpha$ has been shown to exert potent antiadipogenic effects ${ }^{(40)}$ and induce hepatic steatosis ${ }^{(41)}$.

In a study by Le Roy et $a l .{ }^{(17)}$, it was further confirmed that insulin resistance develops separately from obesity. However, they did not observe differences in TNF- $\alpha$ levels, and suggested that the gut microbiota may affect hepatic metabolism through other mechanisms, independent of the immune system (Fig. 5). As an example of a different mechanism, in a lipidomic study, Velagapudi et al. ${ }^{(42)}$ suggested that the increase in phosphatidylcholine $(16: 0 / 18: 1)$

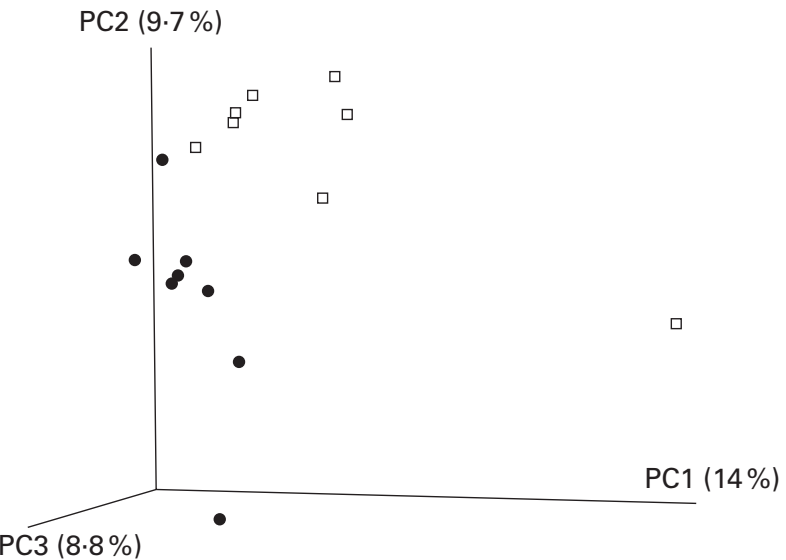

Fig. 3. Principal coordinate (PC) analysis based on (a) weighted Unifrac and (b) unweighted Unifrac distance matrices in mice ( $n 8$ per group) fed a diet supplemented with trans-10, cis-12-conjugated linoleic acid $(\square)$ or with no supplementation $(\bullet)$. 

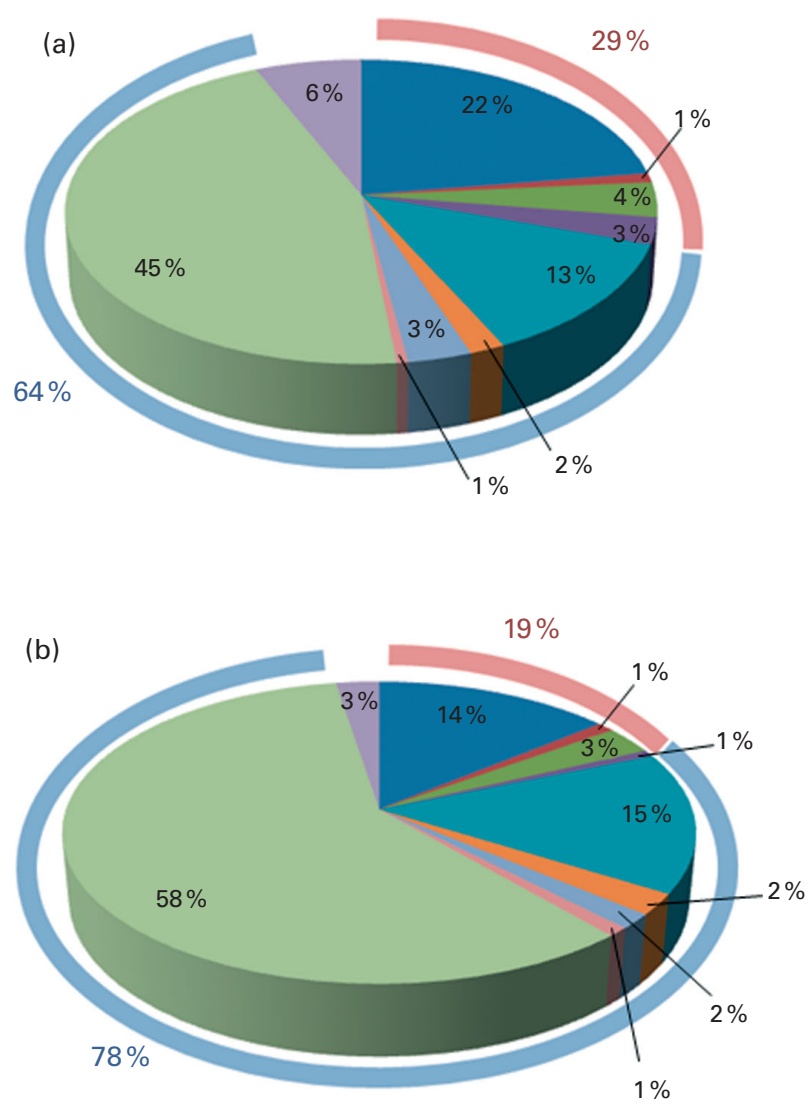

Fig. 4. Gut microbiota composition in mice fed a diet supplemented with trans-10, cis-12-conjugated linoleic acid (t10c12-CLA) (a) or with no supplementation (b). The microbiota composition was altered by $t 10 c 12-C L A$ intake, as determined by pyrosequencing of $16 \mathrm{~S}$ rRNA $(n 8)$. Pie charts represent the mean percentage read number for the corresponding colour-coded family (only reads $\geq 1 \%$ are shown). Bacteroidetes: 1 , S24-7; —, Bacteroidaceae; $\square$, Rikenellaceae; $\square$, Porphyromonadaceae. Firmicutes:

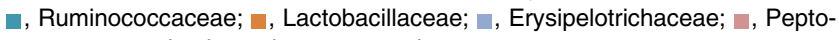

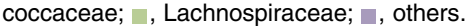

induced by the microbiota may activate lipoprotein lipase, resulting in reduced serum TAG levels together with increased storage of lipids in the adipose tissue and liver. Although we did not examine single lipid classes in the present study, we observed an increase in 16:0 and 18:1 FA in the liver of mice fed with $t 10 c 12$-CLA; therefore, there is a possibility that these animals could have more amounts of $16: 0 / 18: 1$ phospholipids.

We also observed other important changes associated with dietary supplementation of $t 10 c 12$-CLA. There were increased proportions of Porphyromonadaceae and decreased abundance of Lachnospiraceae and Desulfovibrionaceae. Porphyromonadaceae have previously been associated with non-alcoholic fatty liver disease, atherosclerosis and diabetes ${ }^{(43)}$. Members of the family Lachnospiraceae have been shown to protect mice against colonisation by Clostridium difficile ${ }^{(44)}$, whereas enhanced levels of bacteria from the Desulfovibrionaceae family were associated with impaired glucose tolerance and a serious metabolic syndrome phenotype ${ }^{(45)}$. Moreover, in a study by Bajaj et al. ${ }^{(39)}$, Lachnospiraceae abundance was reported to be lower in patients with cirrhosis, while
Porphyromonadaceae abundance was positively correlated with cognitive impairment and inflammation in patients with hepatic encephalopathy.

SCFA are the end products of bacterial fermentation, with acetate, propionate and butyrate being the major SCFA in the mammalian gut. The type and amount of SCFA produced depends on diet, intestinal transit and microbiota composition $^{(46)}$. In the present study, SCFA levels were found to be altered by $t 10 c 12$-CLA supplementation with higher levels of acetate, propionate and isobutyrate detected in the caecal content, even though both groups received a similar amount of carbohydrates and proteins. Thus, the higher amount of SCFA detected in the intervention group was probably due to the marked changes in the microbiota composition induced by dietary $t 10 c 12$-CLA. SCFA are considered important energy sources for the host, and a few studies have suggested a link between increased levels of SCFA and obesity ${ }^{(34,47)}$. However, in the present study, the higher levels of SCFA were associated with lower fat mass. The precise mechanism involved in SCFA modulation of host metabolism is not clear, and the results reported in the literature are conflicting. Thus, in the present study, we propose three explanations for the possible role of SCFA in t10c12-CLA-induced lipoatrophy/liver steatosis: (1) increased propionate induces gluconeogenesis ${ }^{(48)}$; (2) SCFA activate G-protein-coupled receptor 41, stimulating hepatic lipogenesis ${ }^{(49)}$; (3) SCFA activate G-protein-coupled receptor 43 that regulates energy uptake through the adipose tissue, and promotes the utilisation of excess energy in other tissues instead of storage in the adipocytes ${ }^{(50)}$ (Fig. 5).

The fat-lowering effect of $t 10 c 12-C L A$ is complex, involving multiple mechanisms, and previous studies have shown that feeding $t 10 c 12$-CLA triggers changes in the pattern of gene expression, reducing FA uptake and storage in the adipocytes, and favouring lipid accumulation in the liver of mice ${ }^{(12,19,51)}$. In the adipose tissue, $t 10 c 12-C L A$ has been reported to increase (pre)adipocyte apoptosis and reduce adipogenesis and lipogenesis, by the inhibition of key transcription factors $^{(52)}$. The nearly complete absence of adipose tissue reduces the production of leptin by adipocytes, and the release of NEFA, thereby reducing lipid flux to the liver and subsequent VLDL secretion rates ${ }^{(29)}$. Indeed, in the present study, lower serum TAG and leptin levels were observed in the $t 10 c 12$-CLA-supplemented group when compared with the unsupplemented control group. Moreover, t10c12-CLA supplementation markedly increased glucose and insulin concentrations in the serum, compared with no supplementation. Thus, $t 10 c 12$-CLA supplementation may lead to insulin resistance and decreased glucose uptake by adipocytes, as inflammatory cytokines such as TNF- $\alpha$ and IL- 6 down-regulate the expression of lipogenic proteins and the insulin-dependent GLUT 4 (for a review, see Bäckhed et al. ${ }^{(31)}$ ). High levels of circulating insulin and glucose have been reported to induce the expression of sterol regulatory element-binding protein 1c (SREBP-1c) and carbohydrate response elementbinding protein in the liver, and, therefore, stimulate hepatic de novo lipogenesis ${ }^{(53,54)}$.

Another factor that may contribute to the development of liver steatosis is the profound change in the composition 

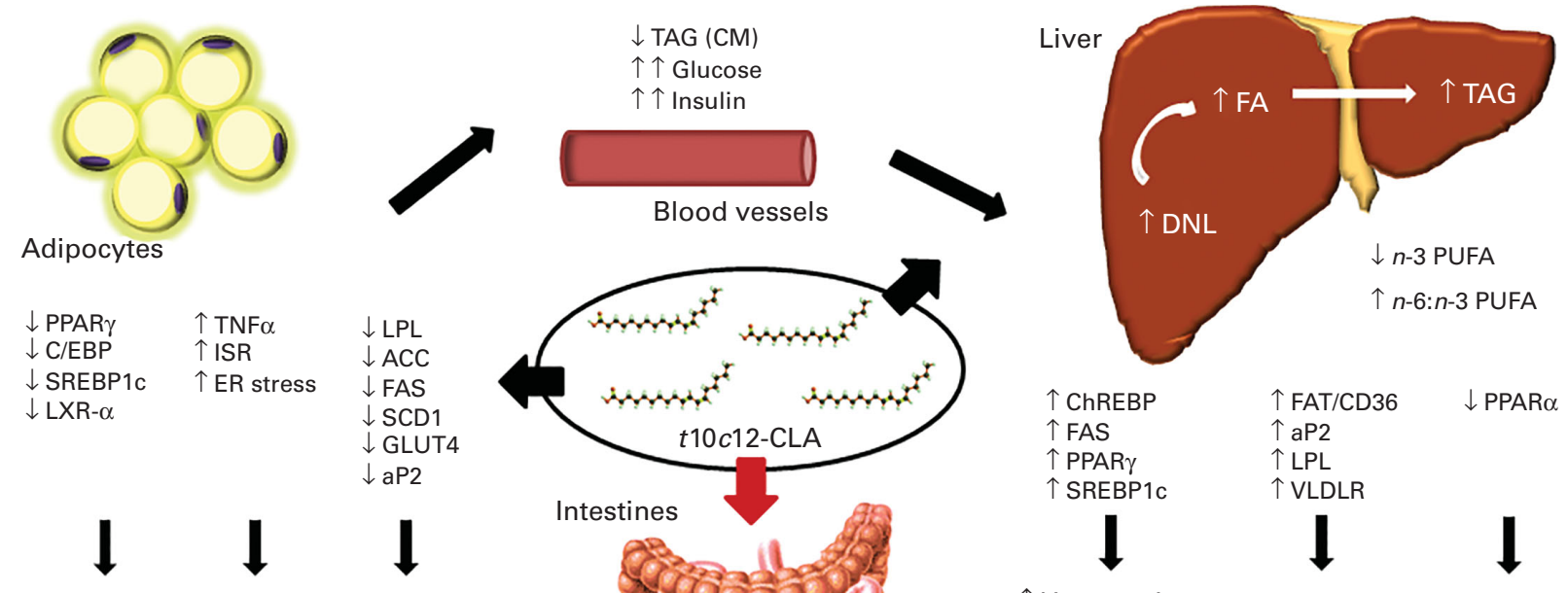

$\begin{array}{ll}\downarrow \text { Adipogenesis } \uparrow \text { Apoptosis } & \downarrow \text { FA uptake } \\ \downarrow \text { Lipogenesis } & \downarrow \text { FA synthesis } \\ & \downarrow \text { Glucose uptake }\end{array}$

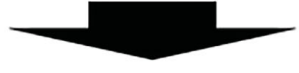

$\downarrow$ Visceral fat mass

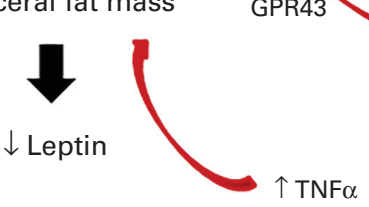

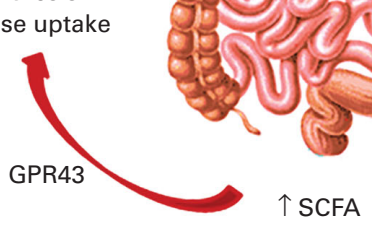

$\uparrow$ SCFA

Intestines

$\uparrow$ Lipogenesis

$\uparrow$ Gluconeogenesis $\uparrow$ FA uptake $\downarrow$ FA oxidation

Fig. 5. Schematic summary of all the mechanisms of action of trans-10, cis-12-conjugated linoleic acid ( $t 10 c 12-C L A)$, as proposed by the different studies cited in the present paper. There are a variety of proposed mechanisms through which $110 c 12-C L A$ supplementation may cause hepatic steatosis and lipoatrophy in mice. Also, t10c12-CLA up- and down-regulates genes involved in fatty acid (FA) synthesis, uptake and oxidation in the adipose tissue and liver in a direct and an indirect manner (black arrows). In the present study, we propose that the gut microbiota and its products are extra environmental factors affecting host lipid metabolism (red arrows). ACC, acetyl-CoA carboxylase; aP2, adipocyte-specific fatty acid binding protein; C/EBP, CAAT/enhancer-binding protein; ChREBP, carbohydrate response element binding protein; CM, chylomicron; DNL, de novo lipogenesis; ER, endoplasmic reticulum; FAS, fatty acid synthase; FAT/CD36, fatty acid translocase; GPR, G-protein coupled receptor; ISR, integrated stress response; LPL, lipoprotein lipase; LPS, lipopolysaccharide; LXR- $\alpha$, liver X receptor- $\alpha$; SCD1, stearoyl-CoA desaturase; SREBP-1c, sterol regulatory element-binding protein 1c; VLDLR, VLDL receptor.

of long-chain fatty acids in the liver, induced by t10c12-CLA supplementation. The present study showed that $t 10 c 12-\mathrm{CLA}$ intake was associated with an increased n-6 PUFA: $n-3$ PUFA ratio in the liver. Reduced availability of $n-3$ PUFA may increase SREBP-1 expression, and reduce PPAR $\alpha$ expression, stimulating lipogenesis over lipid oxidation, with accumulation of TAG in the liver ${ }^{(55)}$. Furthermore, $t 10 c 12$-CLA supplementation was associated with altered FA composition of other tissues, besides changing liver FA profiles. Our observations confirmed previous reports demonstrating that t10c12-CLA supplementation decreased arachidonic acid, and altered the ratio of SFA:MUFA, especially increasing the amount of palmitic acid over palmitoleic acid ${ }^{(6,28,56)}$. Although the exact mechanism of CLA action on tissue FA composition has not been elucidated, a few studies have suggested that the reduction in stearoyl-CoA desaturase activity may impair the conversion of SFA to MUFA ${ }^{(28,35)}$, whereas the inhibition of linoleic acid elongation and desaturation may have an impact on $n-6$ PUFA synthesis ${ }^{(57,58)}$.

Several studies investigating the anti-obesity effect of CLA supplements have focused on gene regulation in the liver and adipose tissue; however, to our knowledge, this is the first study to show the impact of dietary t10c12-CLA on the gut microbiota composition and SCFA production. Long dietary exposure to $t 10 c 12$-CLA transformed the gut microbiota, favouring the growth of harmful bacteria, thus increasing host susceptibility to a variety of diseases. The greater proportions of Bacteroidetes and Porphyromonadaceae bacteria found in the $t 10 c 12$-CLA-supplemented group most probably had an influence on lipid metabolism and induction of hepatic steatosis, with higher levels of SCFA contributing to enhanced lipogenesis and gluconeogenesis in the liver.

Thus, diet plays an important role in the modulation of the gut microbiota composition, and as observed in the present study, a single dietary FA is capable of inducing a systemic effect on the host. Although data on the effects of CLA in human subjects are contradictory, few studies that used purified isomers instead of CLA mixtures have shown a detrimental influence of $t 10 c 12$-CLA, raising concerns about the safety of supplements containing higher amounts of this isomer ${ }^{(59,60)}$. Considering the fact that non-prescription pills 
for weight loss are frequently used as an easier alternative to diet and physical activities ${ }^{(61)}$, more clinical studies of longer duration with larger sample sizes are needed.

Dietary approaches targeting beneficial bacteria and suppressing harmful species may be a new strategy to prevent or treat hepatic steatosis and associated metabolic disorders. The use of FA mixtures with equal proportions of CLA isomers, or the use of probiotics and prebiotics to balance the potentially negative effects of $t 10 c 12$-CLA on the microbiota composition may be alternatives for individuals seeking anti-obesity dietary solutions.

\section{Acknowledgements}

The authors acknowledge Eoin Barrett, Alan Hennessy and Talia Huffe for their technical assistance.

The present study was supported by the Science Foundation of Ireland-funded Centre for Science, Engineering and Technology, the Alimentary Pharmabiotic Centre (grant no. SFI/12/RC/2273).

The authors' responsibilities are as follows: C. S., R. P. R., F. S. and E. M. Q. designed the research; T. M. M. and R. W. conducted the research; T. M. M., R. W. and O. O. analysed the data; T. M. M., R. W., O. O. and C. S. wrote the manuscript; G. F. F., P. D. C., T. G. D. and J. F. C. provided significant advice; C. S. had primary responsibility for the final content.

None of the authors had a conflict of interest.

\section{References}

1. Bhattacharya A, Banu J, Rahman M, et al. (2006) Biological effects of conjugated linoleic acids in health and disease. J Nutr Biochem 17, 789-810.

2. Barrett E, Ross R, Fitzgerald G, et al. (2007) Rapid screening method for analyzing the conjugated linoleic acid production capabilities of bacterial cultures. Appl Environ Microbiol 73, 2333-2337.

3. Coakley M, Ross R, Nordgren M, et al. (2003) Conjugated linoleic acid biosynthesis by human-derived Bifidobacterium species. J Appl Microbiol 94, 138-145.

4. Lee K, Paek K, Lee $\mathrm{H}$, et al. (2007) Antiobesity effect of trans-10, cis-12-conjugated linoleic acid-producing Lactobacillus plantarum PL62 on diet-induced obese mice. J Appl Microbiol 103, 1140-1146.

5. Wall R, Ross RP, Shanahan F, et al. (2009) Metabolic activity of the enteric microbiota influences the fatty acid composition of murine and porcine liver and adipose tissues. Am J Clin Nutr 89, 1393-1401.

6. Kelley DS, Bartolini GL, Newman JW, et al. (2006) Fatty acid composition of liver, adipose tissue, spleen, and heart of mice fed diets containing $t 10, c 12-$, and $c 9, t 11$-conjugated linoleic acid. Prostaglandins Leukot Essent Fatty Acids $\mathbf{7 4}$, 331-338.

7. Kritchevsky D, Tepper SA, Wright S, et al. (2004) Conjugated linoleic acid isomer effects in atherosclerosis: growth and regression of lesions. Lipids 39, 611-616.

8. Toomey S, Harhen B, Roche HM, et al. (2006) Profound resolution of early atherosclerosis with conjugated linoleic acid. Atherosclerosis 187, 40-49.

9. Wilson T, Nicolosi R, Chrysam M, et al. (2000) Conjugated linoleic acid reduces early aortic atherosclerosis greater than linoleic acid in hypercholesterolemic hamsters. Nutr Res 20, 1795-1805.

10. Yang M \& Cook ME (2003) Dietary conjugated linoleic acid decreased cachexia, macrophage tumor necrosis factor- $\alpha$ production, and modifies splenocyte cytokines production. Exp Biol Med 228, 51-58.

11. Yu Y, Correll P \& Vanden Heuvel J (2002) Conjugated linoleic acid decreases production of pro-inflammatory products in macrophages: evidence for a PPAR $\gamma$-dependent mechanism. Biochim Biophys Acta 1581, 89-99.

12. Clément L, Poirier H, Niot I, et al. (2002) Dietary trans-10, cis-12 conjugated linoleic acid induces hyperinsulinemia and fatty liver in the mouse. J Lipid Res 43, 1400-1409.

13. Liu X, Joseph SV, Wakefield AP, et al. (2012) High dose trans-10, cis-12 CLA increases lean body mass in hamsters, but elevates levels of plasma lipids and liver enzyme biomarkers. Lipids 47, 39-46.

14. Salas-Salvado J, Marquez-Sandoval F \& Bullo M (2006) Conjugated linoleic acid intake in humans: a systematic review focusing on its effect on body composition, glucose, and lipid metabolism. Criti Rev Food Sci Nutr 46, 479-488.

15. Park Y \& Pariza MW (2007) Mechanisms of body fat modulation by conjugated linoleic acid (CLA). Food Res Int 40, 311-323.

16. Wang Y \& Jones PJ (2004) Dietary conjugated linoleic acid and body composition. Am J Clin Nutr 79, 1153S-1158S.

17. Le Roy $T$, Llopis M, Lepage $\mathrm{P}$, et al. (2013) Intestinal microbiota determines development of non-alcoholic fatty liver disease in mice. Gut 62, 1787-1794.

18. Tamura S \& Shimomura I (2005) Contribution of adipose tissue and de novo lipogenesis to nonalcoholic fatty liver disease. J Clin Invest 115, 1139-1142.

19. Vyas D, Kadegowda AKG \& Erdman RA (2011) Dietary conjugated linoleic Acid and hepatic steatosis: speciesspecific effects on liver and adipose lipid metabolism and gene expression. J Nutr Metab 2012, 932928.

20. Quigley EM \& Monsour HP (2013) The gut microbiota and the liver: implications for clinical practice. Expert Rev Gastroenterol Hepatol 7, 723-732.

21. Bajaj JS, Hylemon PB \& Younossi Z (2012) The intestinal microbiota and liver disease. Am J Gastroenterol Suppl 1, 9-14.

22. Folch J, Lees M \& Sloane-Stanley G (1957) A simple method for the isolation and purification of total lipids from animal tissues. J biol Chem 226, 497-509.

23. Park P \& Goins R (1994) In situ preparation of fatty acid methyl esters for analysis of fatty acid composition in foods. J Food Sci 59, 1262-1266.

24. Caporaso JG, Kuczynski J, Stombaugh J, et al. (2010) QIIME allows analysis of high-throughput community sequencing data. Nat Methods 7, 335-336.

25. Huson DH, Auch AF, Qi J, et al. (2007) MEGAN analysis of metagenomic data. Genome Res 17, 377-386.

26. Price MN, Dehal PS \& Arkin AP (2010) FastTree 2 - approximately maximum-likelihood trees for large alignments. PloS ONE 5, e9490.

27. Chen VB, Davis IW \& Richardson DC (2009) KING (Kinemage, Next Generation): a versatile interactive molecular and scientific visualization program. Protein Sci 18, 2403-2409.

28. House RL, Cassady JP, Eisen EJ, et al. (2005) Functional genomic characterization of delipidation elicited by trans-10, cis-12-conjugated linoleic acid (t10c12-CLA) in a polygenic obese line of mice. Physiol Genomics 21, 351-361.

29. Degrace P, Moindrot B, Mohamed I, et al. (2006) Upregulation of liver VLDL receptor and FAT/CD36 expression in 
LDLR - / - apoB100/100 mice fed trans-10, cis-12 conjugated linoleic acid. J Lipid Res $\mathbf{4 7}, 2647-2655$.

30. Tremaroli V \& Bäckhed F (2012) Functional interactions between the gut microbiota and host metabolism. Nature 489, 242-249.

31. Bäckhed F, Ding H, Wang T, et al. (2004) The gut microbiota as an environmental factor that regulates fat storage. Proc Natl Acad Sci U S A 101, 15718-15723.

32. Bäckhed F, Manchester JK, Semenkovich CF, et al. (2007) Mechanisms underlying the resistance to diet-induced obesity in germ-free mice. Proc Natl Acad Sci U S A 104, 979-984

33. Ley RE, Bäckhed F, Turnbaugh P, et al. (2005) Obesity alters gut microbial ecology. Proc Natl Acad Sci U S A 102, $11070-11075$.

34. Turnbaugh PJ, Hamady M, Yatsunenko T, et al. (2009) A core gut microbiome in obese and lean twins. Nature 457 , 480-484.

35. Ley RE, Turnbaugh PJ, Klein S, et al. (2006) Microbial ecology: human gut microbes associated with obesity. Nature 444, 1022-1023

36. Larsen N, Vogensen FK, van den Berg FW, et al. (2010) Gut microbiota in human adults with type 2 diabetes differs from non-diabetic adults. PloS ONE 5, e9085.

37. Membrez M, Blancher F, Jaquet M, et al. (2008) Gut microbiota modulation with norfloxacin and ampicillin enhances glucose tolerance in mice. FASEB J 22, 2416-2426.

38. Virkamäki A \& Yki-Järvinen H (1994) Mechanisms of insulin resistance during acute endotoxemia. Endocrinol 134, 2072-2078.

39. Bajaj JS, Ridlon JM, Hylemon PB, et al. (2012) Linkage of gut microbiome with cognition in hepatic encephalopathy. Am J Physiol Gastrointest Liver Physiol 302, G168-G175.

40. Petruschke $\mathrm{T} \&$ \& Hauner H (1993) Tumor necrosis factoralpha prevents the differentiation of human adipocyte precursor cells and causes delipidation of newly developed fat cells. J Clin Endocrinol Metab 76, 742-747.

41. Yang SQ, Lin HZ, Lane MD, et al. (1997) Obesity increases sensitivity to endotoxin liver injury: implications for the pathogenesis of steatohepatitis. Proc Natl Acad Sci 94, $2557-2562$

42. Velagapudi VR, Hezaveh R, Reigstad CS, et al. (2010) The gut microbiota modulates host energy and lipid metabolism in mice. J Lipid Res 51, 1101-1112.

43. Henao-Mejia J, Elinav E, Jin C, et al. (2012) Inflammasomemediated dysbiosis regulates progression of NAFLD and obesity. Nature 482, 179-185.

44. Reeves AE, Koenigsknecht MJ, Bergin IL, et al. (2012) Suppression of clostridium difficile in the gastrointestinal tracts of germfree mice inoculated with a murine isolate from the family Lachnospiraceae. Infect Immun 80, 3786-3794.

45. Zhang C, Zhang M, Wang S, et al. (2010) Interactions between gut microbiota, host genetics and diet relevant to development of metabolic syndromes in mice. ISME $J \mathbf{4}$, 232-241.
46. Macfarlane GT \& Macfarlane S (2012) Bacteria, colonic fermentation, and gastrointestinal health. J AOAC Int $\mathbf{9 5}$, $50-60$.

47. Turnbaugh PJ, Ley RE, Mahowald MA, et al. (2006) An obesity-associated gut microbiome with increased capacity for energy harvest. Nature 444, 1027-1131.

48. Wolever T, Spadafora P \& Eshuis H (1991) Interaction between colonic acetate and propionate in humans. Am J Clin Nutr 53, 681-687.

49. Samuel BS, Shaito A, Motoike T, et al. (2008) Effects of the gut microbiota on host adiposity are modulated by the short-chain fatty-acid binding $G$ protein-coupled receptor, Gpr41. Proc Natl Acad Sci U S A 105, 16767-16772.

50. Kimura I, Ozawa K, Inoue D, et al. (2013) The gut microbiota suppresses insulin-mediated fat accumulation via the short-chain fatty acid receptor GPR43. Nat Commun 4, 1829.

51. Jourdan T, Djaouti L, Demizieux L, et al. (2009) Liver carbohydrate and lipid metabolism of insulin-deficient mice is altered by trans-10, cis-12 conjugated linoleic acid. I Nutr 139, 1901-1907

52. Kennedy A, Martinez K, Schmidt S, et al. (2010) Antiobesity mechanisms of action of conjugated linoleic acid. J Nutr Biochem 21, 171-179.

53. Shimomura I, Bashmakov Y \& Horton JD (1999) Increased levels of nuclear SREBP-1c associated with fatty livers in two mouse models of diabetes mellitus. J Biol Chem 274, 30028-30032

54. Yamashita H, Takenoshita M, Sakurai M, et al. (2001) A glucose-responsive transcription factor that regulates carbohydrate metabolism in the liver. Proc Natl Acad Sci U S A 98, 9116-9121.

55. El-Badry AM, Graf R \& Clavien P-A (2007) Omega 3-Omega 6: what is right for the liver? J Hepatology 47, 718-725.

56. Evans ME, Brown JM \& McIntosh MK (2002) Isomer-specific effects of conjugated linoleic acid (CLA) on adiposity and lipid metabolism. J Nutr Biochem 13, 508-516.

57. Eder K, Slomma N \& Becker K (2002) Trans-10, cis-12 conjugated linoleic acid suppresses the desaturation of linoleic and $\alpha$-linolenic acids in HepG2 cells. J Nutr 132, $1115-1121$

58. Lin X, Bo J, Oliver SAM, et al. (2011) Dietary conjugated linoleic acid alters long chain polyunsaturated fatty acid metabolism in brain and liver of neonatal pigs. $J$ Nutr Biochem 22, 1047-1054.

59. Risérus U, Arner P, Brismar K, et al. (2002) Treatment with dietary trans 10 cis 12 conjugated linoleic acid causes isomerspecific insulin resistance in obese men with the metabolic syndrome. Diabetes Care 25, 1516-1521.

60. Tricon S, Burdge GC, Kew S, et al. (2004) Opposing effects of cis-9, trans-11 and trans-10, cis-12 conjugated linoleic acid on blood lipids in healthy humans. Am J Clin Nutr 80, 614-620.

61. Saper RB, Eisenberg DM \& Phillips RS (2004) Common dietary supplements for weight loss. Am Family Physician 70, $1731-1740$ 